\title{
ANÁLISE DOS DIREITOS AUTORAIS NO ENSINO A DISTÂNCIA
}

\author{
Marina Veloso Mourão ${ }^{1}$ \\ Frederico de Andrade Gabrich ${ }^{2}$
}

Resumo: A modalidade de ensino a distância é a que mais cresce no Brasil e está a cada dia mais presente na vida da população, ávida pela informação, por tecnologia, pelo acesso ao conhecimento e pelos custos baixos na educação. Nesse contexto, o presente estudo propõe analisar, com fundamento no método dedutivo, a tutela autoral do material didático criado e produzido para os cursos lecionados na modalidade de ensino a distância, considerando as recentes transformações sociais, os novos desafios para a educação e tendo como marco teórico a Lei ${ }^{\circ}$ 9.610/98, que regula os direitos autorais no Brasil (LDA).

Palavras-chave: Direitos autorais; Coautoria; Novas tecnologias; Ensino a distância; Educação.

\section{ANALYSIS OF COPYRIGHT IN ONLINE COURSES}

Abstract: The distance learning method is getting very popular in Brazil and is increasingly present in the lives of the population, eager for information, technology, access to knowledge and low costs in education. In this context, the present study proposes to analyze, based on the deductive method, the copyright protection of the educational materials created and produced for courses taught in the distance education modality, considering the recent social transformations, the new challenges for education and having as theoretical framework the Law 9.610 / 98, which regulates copyright in Brazil (LDA).

Keywords: Copyrights; Co-authoring; New technologies; Distance learning; Education.

\section{INTRODUÇÃO}

A combinação do ensino a distância (EAD) com as tecnologias da informação e comunicação (TICs) tem sido cada vez mais empregada como opção de formação educacional nas mais diversas áreas de conhecimento, desde o ensino tecnológico, ao profissionalizante e acadêmico. O EAD permite aos alunos moldar a rotina dos estudos de acordo com as suas necessidades. Além disso, no plano formal, o diploma emitido por uma instituição de ensino que oferece cursos em EAD e que tenha autorização e reconhecimento do Ministério da Educação (MEC) tem o mesmo valor que o diploma de um curso presencial, sendo geralmente oferecido por com um custo muito inferior se comparado aos mesmos cursos de

\footnotetext{
${ }^{1}$ Mestranda em Direito Privado pela Universidade Fumec. Mestre em Direito do Design pela Université Lumière Lyon 2. Graduada em Direito pela UFMG. marinavmourao@gmail.com

${ }_{2}$ Doutor, mestre e especialista em Direito Comercial/Empresarial pela UFMG. Professor Adjunto da Universidade Fumec. fredericogabrich@fumec.br
} 
ensino presencial. Especificamente no âmbito jurídico, atualmente são numerosas as ofertas de cursos de pós-graduação latu sensu cuja totalidade do conteúdo ministrado, bem como das atividades de fixação e avaliativas são realizados exclusivamente online e/ou a distância. Nesses cursos, virtual também é a relação entre o aluno e os professores, e esta ocorre, geralmente, por intermédio da disponibilização de canais de dúvidas (privados e/ou públicos) e fóruns de discussões.

Apesar de ser a modalidade de ensino que mais cresce no país, ganhando espaço e reconhecimento, principalmente na última década, o EAD, por ser um modelo de ensino relativamente novo, ainda tem gerado opiniões divergentes no meio acadêmico e profissional acerca de sua viabilidade e eficiência. E isso não é diferente no meio jurídico, apesar de ainda não existirem cursos de graduação em Direito exclusivamente a distância.

De fato, esse preconceito, observado no mercado de trabalho em relação a alguns profissionais formados ou pós-graduados a distância, às vezes não tem motivação específica, mas outras vezes decorre da análise das eventuais falhas ou deficiências das metodologias e dos métodos de ensino usados nesses cursos, bem como também decorre da constatação da deficiência de formação dos alunos.

Ocorre que tais fragilidades são relativas, pois podem ocorrer também no ensino presencial, mas podem ser superadas mediante o adequado planejamento estratégico dos conteúdos, do material didático, das metodologias e dos métodos de ensino, de aprendizagem e de avaliação usados nesses cursos a distância. Nesse sentido, destaca-se a atuação profissional estratégica do designer instrucional, que geralmente é um profissional qualificado, experiente e capaz de desenvolver estratégias voltadas para o melhor aproveitamento possível do ensino a distância, mediante a adequação do conteúdo, das metodologias de ensino e de aprendizagem, das narrativas dos professores, das mídias utilizadas e do material didático-instrucional empregado.

O planejamento estratégico do ensino a distância, todavia, normalmente não resolve um problema jurídico ainda recorrente do EAD: a disponibilização, a utilização e a reprodução indefinida do material didático-instrucional produzido para o EAD, sem o pagamento específico e repetido de uma remuneração pelos direitos patrimoniais de autor.

Este é o problema que esta pesquisa propõe enfrentar, com fundamento no método hipotético-dedutivo e tendo como marco teórico o disposto na Lei de Direitos Autorais brasileira (Lei n. 9.610/98) (LDA). 
Assim, pretende-se demonstrar com a pesquisa que, diante da complexidade em relação aos direitos autorais relativos ao material didático-instrucional dos cursos EAD, cujo conteúdo muitas vezes é produzido por diversos professores e de forma colaborativa, no sistema de inovação aberta, é necessário repensar a forma de produção e de remuneração dos autores desse material, ou até readequar a legislação de direito autorais à realidade contemporânea, que ainda não existia, em toda a sua dimensão e importância, na época de formulação da Lei n. 9.610/98.

\title{
2 O ENSINO A DISTÂNCIA
}

No Brasil, no plano jurídico, a educação é tratada como um valor de cidadania e de dignidade da pessoa humana e isso decorre expressamente do disposto no texto constitucional, segundo o qual:

\begin{abstract}
Art. 205. A educação, direito de todos e dever do Estado e da família, será promovida e incentivada com a colaboração da sociedade, visando ao pleno desenvolvimento da pessoa, seu preparo para o exercício da cidadania e sua qualificação para o trabalho (BRASIL, 1988).
\end{abstract}

Nessa mesma perspectiva, a Lei n. 9.394/96, dispõe sobre as Diretrizes e Bases da Educação (LDB), e estabelece que o ensino presencial e a distância devem ser estruturados de forma a se complementarem, com vistas ao aperfeiçoamento, ao desenvolvimento do cidadão e à sua inclusão social e profissional.

Presencial ou a distância, o ensino pode ser exercido por iniciativas de instituições públicas ou privadas, que são devidamente fiscalizadas pelo Estado, na forma da legislação de regulação da atividade educacional. Nesse sentido, especificamente quanto ao EAD, este é atualmente disciplinado pelo Decreto $\mathrm{n}^{\circ}$ 9.057/2017, que regulamentou o disposto no artigo 80 da LDB.

$\operatorname{Dados}^{3}$ recentes do Ministério da Educação (MEC), demonstram que o EAD é a modalidade de ensino que mais cresce no Brasil. Por ser quase inteiramente online ou a distância, o EAD é oferecido por meio da internet e o discente pode assistir às aulas no horário em que desejar pelo computador, tablet ou smartphone e isso, na prática, significa flexibilidade e mobilidade adequável aos mais diversos estilos de vida e capacidades econômicas dos alunos.

\footnotetext{
${ }^{3}$ MEC (Ministério da Educação). Disponível em: <http://portal.mec.gov.br/docman/setembro-2018-pdf/97041apresentac-a-o-censo-superior-u-ltimo/file> Acesso em: 4 jul. 2019.
} 
Com aumento da intensidade e da evolução das TICs nos últimos anos, ampliou-se o campo de atuação do ensino a distância nas mais diversas áreas do conhecimento. A melhora na infraestrutura da internet, aliada ao desenvolvimento dos softwares e dos hardwares, fomenta a oferta crescente de cursos nessa modalidade nas mais diversas áreas de conhecimento, com custos cada vez mais baixos.

Por isso, de acordo com Santana e Giraffa (2018), apesar de ainda enfrentar certa resistência dos setores mais tradicionais da educação, o EAD tem se firmado como uma modalidade de ensino e de aprendizagem que propicia a efetivação do direito fundamental à educação, principalmente em regiões carentes de recursos e de possibilidades de desenvolvimento do ensino presencial. Nesse sentido, segundo as mencionadas autoras:

\begin{abstract}
Mesmo sofrendo críticas, cresce a aposta e o investimento do poder público e da iniciativa privada na $\mathrm{EaD}$, como uma modalidade de se fazer Educação que vem se revelando em uma verdadeira quebra de paradigma na educação superior. Sabe-se que a Educação a Distância é uma modalidade de ensino e aprendizagem que requer vontade, querer, em síntese, disciplina do aluno. $\mathrm{O}$ aluno da $\mathrm{EaD}$, em regra, é aquele que sabe estudar sozinho, ou melhor, ele quer sair do estado de "menoridade" e deseja atingir a "maioridade" ele almeja e precisa se tornar um ser humano autônomo, crítico e formador de opinião (SANTANA; GIRAFFA, 2018, p.133).
\end{abstract}

Com as novas tecnologias e o EAD, é possível a inserção de mudanças significativas no processo educacional, capazes de promover não apenas a eficácia plena do princípio constitucional, mas também um tipo de ensino mais dinâmico e capaz de contribuir, de fato, para o exercício pleno da cidadania e para a preparação do cidadão para a vida do trabalho.

Todavia, isso somente é possível mediante o planejamento estratégico da educação a distância, das práticas pedagógicas e andragógicas (já que o EAD se destina sobretudo ao ensino de adultos), com a formulação e/ou com a reformulação dos conteúdos, das narrativas dos professores, do material didático-instrucional e das formas de avaliação.

A eficácia plena e crescente do ensino a distância, exige, antes de tudo, reconhecer que não basta reproduzir em vídeo-aulas os conteúdos, as narrativas, as metodologias e os métodos de ensino tradicionais, que geralmente são instrutivistas, monológicos, dogmáticos e pressupõem uma atitude absolutamente passiva do aluno. Isso é mais verdadeiro, ainda, em relação ao ensino superior de graduação e de pós-graduação, em que é cada vez mais fundamental a conciliação entre a teoria e a prática.

Nessa perspectiva nova, a avaliação dos processos educacionais a distância, dos professores, dos conteúdos, do material didático-instrucional e das formas de avaliação, precisam ser realizadas também a partir de novos paradigmas, especificamente desenvolvidos 
para essa realidade, quer pelas instituições de ensino, quer pelo Estado, quer pelos próprios alunos. Não é exatamente isso que vem acontecendo como regra geral, apesar dos avanços verificados em muitas instituições de ensino que, muitas vezes provocadas pelo Estado, instituem comissões e órgãos internos de avaliação e de aprimoramento do ensino a distância. Todavia, em muitos casos, não se verifica o mesmo cuidado dispensado na avaliação, com o planejamento e com a formatação dos cursos, dos conteúdos, das narrativas, do material didático-instrucional, bem como com o treinamento e com a requalificação dos professores.

Por tudo isso, verifica-se que essa forma de ensino (a distância), nem sempre atinge todos os seus objetivos ou agrada àqueles que têm uma expectativa ainda voltada à lógica de organização do ensino presencial tradicional, ou àqueles alunos que possuem algum tipo de dificuldade com a gestão do tempo, com a disciplina e com a auto-organização. A falta de contato pessoal com professores, demais alunos e com o ambiente universitário também pode ter uma desvantagem para quem ainda não desenvolveu o hábito de estudar sozinho, desafio a ser superado pela atual geração de estudantes do EAD.

Acerca do atual momento histórico, Santana e Giraffa (2018) discorrem:

\begin{abstract}
Mudanças onde o ciberdocente da EaD deverá perpassar pela criação de estímulos ao raciocínio do discente, fazendo com que este passe a pensar criticamente e possibilite a sua formação cidadã e de sua autonomia, por meio de uma aprendizagem mais humana, interativa e que conduza ao processo de reconhecimento e criatividade dos estudantes em regra podada no sistema clássico, esse é o grande desafio (SANTANA; GIRAFFA, 2018, p.134).
\end{abstract}

Compete, então, não apenas aos professores, mas também aos designers instrucionais, com o auxílio dos recursos tecnológicos e comunicacionais, a tarefa de transpor os obstáculos da estruturação contemporânea do EAD por meio da produção de material didático que realmente auxilie os agentes da aprendizagem (docentes e discentes) a superarem as distâncias espaciais e/ou temporais, bem como as eventuais deficiências do EAD.

Sobre o assunto, asseveram Simão Neto e Hesketh (2009):

A distribuição de uma videoaula, quando transmitida ao vivo pela internet difere da mesma aula quando gravada em estúdio sem alunos. O meio de distribuição da aula impõe certos limites e abre certas possibilidades comunicativas que o distinguem de outros meios e assim acrescentam diversos significados. Por isso uma aula ao vivo e sua gravação não são nunca a mesma coisa, assim como uma obra de arte e sua reprodução não são idênticas, cada uma suscita significados também pela forma de sua circulação na sociedade. No mundo contemporâneo, as mídias de distribuição já se transformaram em mídias de produção, meios digitais como smartphones e internet são exemplos tanto de meios de produção como de distribuição de textos, sons, vídeos, imagens produzidos por discentes e docentes e enviados e recebidos continuamente. [...] Sem a sua participação como intérprete e articulador, a comunicação não se processa. Educadores, autores, designers instrucionais, produtores e distribuidores podem fazer o seu trabalho indefinidamente, porém se os 
alunos não tiverem vez e voz para "fazerem sentido" a partir do que receberem, a comunicação não acontecerá - e a aprendizagem sofrerá com isso, se não for de todo impedida. $\mathrm{O}$ design tem uma função muito importante na interpretação também, pois dependendo do design um dado discurso pode vir a ser interpretado muito diferentemente do que se pretendia, ou nem chegar a ser compreendido por quem o deveria interpretar (SIMÃO NETO; HESKETH, 2009, p.63).

\subsection{A importância do design instrucional}

O conjunto de técnicas, métodos e recursos distintos para o planejamento de material de ensino e melhora na aprendizagem por parte dos alunos e usuários é conhecido como design instrucional ou ainda design pedagógico, design educacional, desenho de materiais ou projetos de ensino. É a partir do design instrucional que se constrói a didática educacional e a produção de materiais didáticos tanto para o ensino tradicional como para o EAD.

O design instrucional está relacionado ao desenvolvimento de aulas, cursos e à elaboração de materiais didáticos como as vídeo-aulas, materiais escritos, softwares, ambientes virtuais de aprendizagem ou qualquer outra forma de aprendizagem que facilite o desenvolvimento de práticas pedagógicas transformadoras.

Logo, cabe ao designer instrucional antecipar e suprimir as eventuais dificuldades que possam surgir ao longo processo de aprendizagem, por meio do planejamento do material, dos métodos e das técnicas que serão usadas no decorrer do curso. O designer elaborará materiais que permitam uma aprendizagem efetiva e significativa além de adequar este material ao perfil dos alunos aos quais será dirigido.

Para os autores Simão Neto e Hesketh (2009):

$\mathrm{O}$ design instrucional pode ser definido como um processo que busca o comprometimento com a melhoria da aprendizagem, a atenção para as necessidades do discente e o design de recursos de apoio e incentivo à aprendizagem ativa.

Portanto, o design instrucional pode ser visto como a ponte ente o discurso pedagógico e sua materialização na forma de produtos educacionais, tais como cursos, aulas, livros, vídeos, apostilas, posters, bem como apresentações auxiliadas por computadores e softwares. Na EAD especificamente, vamos tomar design instrucional como processo de conceituação, concepção, antecipação, proposta, planejamento, projeto, criação, desenho, elaboração e especificação de processos, materiais e atividades de aprendizagem a distância (SIMÃO NETO; HESKETH 2009, p.65).

Dessa forma, pode-se afirmar que o design instrucional é a conexão entre o discurso (conjunto de ideias, informações, teorias, opiniões e explicações) e a realização, pois é por meio dele que visualiza-se, antecipa-se aquilo que se pretende produzir. No EAD o discurso pedagógico pode ser realizado, por meio de um reunião entre professores, em uma vídeo-aula, em um artigo científico ou até em uma matéria jornalística. 
No ensino a distância ou no ensino presencial, a elaboração dos materiais didáticos criados para as aulas é realizada por meio da integração do design instrucional com o design de atividades aprendizagem focada na sistematização da proposta educacional centrada na interação entre alunos e professores. Como esclarecem Simão Neto e Hesketh (2009):

O design de atividades de aprendizagem focaliza a criação, a elaboração e a oferta de uma série de ações que os alunos realizam durante sua rota de aprendizagem em um curso, disciplina, aula, oficina ou qualquer outro tipo de prática educativa, formal ou não formal. Visa sistematizar uma proposta educacional centrada na ação de alunos e professores, deslocando o foco da mera transmissão de "conteúdos" para as atividades realizadas efetivamente pelos agentes de aprendizagem. Para tanto estabelece uma tipologia de atividades de aprendizagem baseada nas diferentes formas de "mobilização" das capacidades mentais dos agentes envolvidos (SIMÃO NETO; HESKETH, 2009, p. 97).

Na metodologia de design de atividades de aprendizagem, as atividades de exploração não se reduzem à exposição de conteúdos e à sua memorização. Nela, as atividades de exploração constituem a relação primeira dos alunos com as informações selecionadas pelo professor e pelos autores dos materiais didáticos e de referência para comporem o "conteúdo" do curso, da disciplina e da aula. São o primeiro contato com o universo da informação em sua dimensão ainda linear, vão além da simples narrativa "sobre" um tema e buscam envolver o aluno com ações menos passivas que a do "espectador" de aulas (SIMÃO NETO; HESKETH, 2009, p. 99).

A educação que a sociedade atual demanda pressupõe um espaço onde os interlocutores sejam sujeitos ativos e participantes do processo. Uma educação na qual é permitida a participação, a coautoria, uma aprendizagem baseada numa rede de relações, pressupondo, portanto, possibilidades comunicativas. Podemos entender como uma educação que permite a interatividade (SIMÃO NETO; HESKETH, 2009, p. 118).

Pode-se dizer que, com as técnicas do design de aprendizagem e do design instrucional é possível pensar na personalização do ensino e nas estratégias de promoção do desenvolvimento dos estudantes, ao mesmo tempo em que se respeita as limitações e os talentos individuais, o que é extremamente relevante para a maior eficácia do EAD.

\subsection{Processo criativo e difusão de conhecimento no EAD}

O direito autoral protege a exteriorização de uma ideia, ou seja, uma criação do espírito expressa por qualquer meio ou fixada em qualquer suporte. Uma lição oral, anotações, vídeo-aulas e demais materiais didáticos originais podem ser considerados obras intelectuais e sujeitos a proteção específica. Cabe aos criadores/autores distinguir a produção do conhecimento contida em determinada obra da informação nela existente, pois a informação é de livre circulação, e só será protegida se recombinada em uma obra original. Como bem elucidado por Wachowicz (2015):

Atualmente a produção do conhecimento nas universidades em nível mundial passou a ser estruturada com base em um ambiente tecnológico advindo da revolução das 
novas tecnologias da informação e comunicação (TIC), na qual a produção de conhecimento e a inovação tecnológica passam a ser percebidas como instrumentos imprescindíveis para o desenvolvimento da pesquisa. O impacto dessas novas tecnologias no ambiente universitário é incontestável, seja no fazer em sala de aula, na prática da docência seja na produção da pesquisa. Enfim, todas as atividades acadêmicas absorveram o uso das TIC, a ponto de hoje ser impensável sua realização sem o uso de ferramentas tecnológicas nas quais se destacam, a título de exemplo: a aprendizagem em rede, a produção colaborativa de materiais educacionais, e o ensino a distância (WACHOWICZ, 2015, p. 97).

Com a ampla oferta de cursos EAD considera-se necessário discutir o papel do direito autoral na construção colaborativa do conhecimento através da utilização de recursos educacionais e das novas tecnologias.

O EAD utiliza um sistema de comunicação bidirecional para substituir a interação pessoal em sala de aula entre professor e aluno pela ação sistemática e conjunta de diversos recursos didáticos, inclusive com apoio de uma organização e tutoria, que propicia uma aprendizagem independente e flexível.

Essa modalidade de educação se refere a um processo de ensino-aprendizagem mediado por tecnologias, onde estudantes e tutores estão separados física, espacial e/ou temporalmente, porém, poderão estar conectados mediante tecnologias, sobretudo as telemáticas, a exemplo da internet, ou podendo utilizar outros meios, tais como: correio, rádio, televisão, vídeo, CD-ROM, telefone, fax, salas virtuais, notebooks, entre outras tecnologias semelhantes. A produção do material do EAD utiliza-se dos mais variados recursos audiovisuais para elaborar o material didático em meio digital e compartilhá-lo com os estudantes.

O material produzido para o EAD, enquanto bem intelectual, no ambiente digital, adquire possibilidades de novos contornos e dimensões, inclusive de disponibilização, utilização e reprodução (WACHOWICZ, 2015, p. 102).

E quem seriam os titulares dos eventuais direitos autorais do material criado e produzido para o EAD?

Sobre o tema, Maia e Mattar (2007) estabelecem que:

Tradicionalmente, os professores eram os "donos" do material didático que organizavam para seus cursos presenciais, tanto que podiam "transportá-lo" quando mudavam de uma instituição de ensino para outra, chegando muitas vezes a publicar esse material e receber royalties como autor. A questão que apresenta para a EaD é a seguinte: as faculdades e universidades têm o direito de colocar o material de cursos, organizados por seus professores, online e lucrar com esse material sem que os professores sejam remunerados? Afinal, teria o professor já sido pago para desenvolver seu curso ou apenas para ministrar as aulas, mantendo nesse sentido os direitos de propriedade intelectual sobre o material didático? $\mathrm{Na}$ internet, essa propriedade sobre materiais didáticos tende a ser facilmente perdida. Afinal de contas, quem é o proprietário intelectual do material dos cursos, os professores ou a instituição? (MAIA; MATTAR, 2007, p. 113).

De fato, os cursos de EAD são considerados atividades cientificas dotadas de alto potencial de reutilização. No entanto, existem alguns métodos que não se beneficiam da proteção de direitos autorais, como será demonstrado abaixo.

\section{A TUTELA JURÍDICA DA PRODUÇÃO DE CONHECIMENTO}


Vive-se nos dias atuais em uma sociedade na qual o conhecimento é fator de produção, de geração e de distribuição de poder e riqueza. E, nesse contexto, o direito autoral é um regime jurídico que visa assegurar ao autor de uma obra original o monopólio sobre a sua difusão e utilização. Esse monopólio significa que somente o autor está habilitado a explorar a obra ou a ceder os direitos materiais e patrimoniais sobre ela. O titular do direito autoral pode permitir, dessa maneira, a reprodução, a divulgação, a representação, a distribuição, a edição e a venda dos direitos patrimoniais referentes à sua obra a quem ele bem entender. Esse direito exclusivo do criador sobre a sua obra deve ser respeitado por todos os indivíduos. Por essa razão, deve-se sempre obter autorização do criador da obra e/ou do titular dos direitos patrimoniais de autor antes de reproduzi-la ou de negociá-la.

Nesse sentido, o direito autoral estimula a criação, independe de registro e confere um monopólio econômico de exploração ao seu titular e seus cessionários desde o dia da criação da obra, durante toda a vida do autor e, inclusive, após 70 anos de sua morte, conforme previsto no artigo 41 da Lei n. 9.610/98, segundo o qual:

Art. 41. Os direitos patrimoniais do autor perduram por setenta anos contados de $1^{\circ}$ de janeiro do ano subsequente ao de seu falecimento, obedecida a ordem sucessória da lei civil (BRASIL, 1998).

De fato, o direito autoral não protege a ideia, mas a forma na qual essa ideia é expressa - materializada. A expressão da ideia, fixada de uma forma qualquer, mas não efêmera, torna-se uma obra protegida caso seja original e tenha sido criada através do trabalho e do esforço intelectual do seu autor.

Nesse sentido, inclusive, a doutrina francesa (CARON, 2015, p. 74-89; GAUTIER, 2010, p.48-68) considera que a originalidade é a impressão da personalidade do autor em sua obra. Além disso, o Tribunal de Justiça da União Europeia já determinou que o acesso à proteção pelos direitos autorais necessita da caracterização de uma originalidade que seja: criação intelectual do próprio autor (C-145/10, $\$ 87$ e 88), ao mesmo tempo em que imprima o seu toque pessoal à obra criada (C-145/10, §92) e uma expressão individualizada (C406/10, §41), mas também de escolhas livres e criativas (C-145/10, §§89, 90 e 94) do autor.

Todavia, esse critério de originalidade não deve ser confundido com o mérito artístico da obra e nem tampouco com a novidade. Uma obra pode se beneficiar de originalidade mesmo não sendo nova. Nesse sentido, Christoph Caron (2015, p. 76) menciona o célebre e didático exemplo de DESBOIS (1978): 
Imaginemos dois pintores que decidem, em dias diferentes e sem se consultarem, pintar cada um sua própria tela, no mesmo local, com a mesma luz e a mesma perspectiva. Para o segundo pintor, a paisagem será uma novidade no sentido objetivo da palavra. Entretanto, a falta de novidade não se opõe a uma constatação de originalidade: os dois pintores, de fato, exerceram atividade criativa, tanto um como o outro, trataram do mesmo assunto de maneiras independentemente (...). Ambas as telas constituem obras absolutamente originais (DESBOIS, 1978, apud CARON, 2015, p. 76, tradução nossa). ${ }^{4}$

Outrossim, a Convenção de Berna, da qual o Brasil é signatário, no art. 2.3 faz do critério de originalidade o fundamento para a proteção das obras. Assim, a originalidade é um conceito quase universal para os direitos autorais que também foi consolidado no Acordo TRIPs (sigla em inglês para o Acordo sobre Aspectos dos Direitos de Propriedade Intelectual Relacionados ao Comércio).

\subsection{A lei brasileira de direitos autorais}

A Constituição da República dispõe em seu art. $5^{\circ}$, inciso XXVII que "aos autores pertence o direito exclusivo de utilização, publicação ou reprodução de suas obras, transmissível aos herdeiros pelo tempo que a lei fixar". E a Lei no 9.610, de 1998 regula os direitos autorais no Brasil (LDA).

A LDA apresenta, inicialmente, definições e conceitos, avançando para as obras protegidas, os direitos do autor, as limitações aos direitos do autor e, finaliza com transferências, utilizações e direitos conexos.

$\mathrm{O}$ autor de uma obra é o titular originário (art. $5^{\circ}, \mathrm{XIV}$ ) dos direitos autorais e os adquire no momento em que a criação intelectual é exteriorizada. Existe também, a figura do titular derivado que adquire os direitos do autor por atos inter vivos (cessão de direitos patrimoniais), causa mortis ou disposição legal, respeitados os limites previstos na LDA.

No caput do art. $7^{\circ}$ da LDA é possível verificar a definição de obras intelectuais protegidas como as criações de espírito, expressas por qualquer meio ou fixadas em qualquer suporte, tangível ou intangível, conhecido ou que se invente no futuro e em seus incisos exemplos de obras passíveis de proteção.

Por isso, no contexto específico do EAD, observa-se que são passíveis de proteção

\footnotetext{
${ }^{4}$ Texto original: "Voici deux peintres qui, sans s'être concertés et se promettre un mutuel appui, fixent l'un après l'autre, sur leurs toiles, le même site, dans la même perspective et sous le même éclairage. Le second de ces paysages n'est pas une nouveauté au sens objectif du mot puisque, par hypothèse, le premier a pour sujet le même site. Mais le défaut de nouveauté ne met pas obstacle à la constatation de l'originalité : les deux peintres, en effet, ont déployé une activité créatrice, l'un comme l'autre, en traitant indépendamment l'un de l'autre, le même sujet (...). Elles constituent l'une et l'autre des œuvres absolument originales."
} 
todo o material produzido didático (textos, imagens, sons, projetos, esboços, trabalhos acadêmicos) bem como as vídeo-aulas. Nesse sentido, de acordo com Wachowicz (2013):

\begin{abstract}
A produção do material da EAD utiliza dos recursos informáticos de tratamento de um livro por meio de programas de computadores são inúmeros, a saber: (i) a digitalização do teor do livro por meio de um software de editoração de texto; (ii) a digitalização do livro em si por meio de um software que reproduza a imagem de cada página do livro; (iii) a digitalização do teor do livro que agregue recursos de multimídia sons e imagens; (iv) a digitalização do livro em forma de hipertexto possibilitando que o leitor não tenha apenas uma leitura linear do livro mas navegue em seu conteúdo; (v) a digitalização do livro por meio de softwares interativos que possibilitam ao leitor escolher o final do livro (WACHOWICZ, 2013, p. 10).
\end{abstract}

Já no art. $8^{\circ}$, a lei de direitos autorais brasileira exemplifica o que não são objeto passíveis de proteção, tais como as ideias, procedimentos normativos, sistemas, métodos, projetos ou conceitos matemáticos, esquemas, bem como o aproveitamento industrial ou comercial das ideias contidas nas obras.

A noção de originalidade no sistema brasileiro, assim como no francês, não integra o texto legal. Nesse sentido, tanto no art. 10 da Lei n. 9.610/98, quanto no art. L.112-4 do Code de la Proprieté Intellectuelle (CPI) encontra-se o termo original, ${ }^{5}$ mas somente para a proteção de título de obra. De fato, o legislador brasileiro, inspirado no francês, apresentou somente critérios negativos para a proteção pelos direitos autorais.

Não obstante, a legislação brasileira identifica como autor a pessoa física criadora de obra literária, artística ou científica (art. 11, LDA) e permite que em hipóteses específicas a pessoa jurídica possa receber proteção equiparada à do autor. Além disso, a LDA dispõe que pertencem ao autor os direitos morais e patrimoniais sobre a obra que criou e define tais direitos.

Os direitos morais do autor, irrenunciáveis e inalienáveis, estão enumerados no art. 24 da LDA e são mais restritos, abrangendo os direitos: de reivindicar a autoria; de ser identificado como autor; de conservar obra inédita; de assegurar a integridade da obra; de modificação da obra; de retirar a obra de circulação ou suspender sua utilização em caso de afronta à reputação ou à honra do autor; de acessar exemplar único e raro da obra.

Os direitos patrimoniais do autor, por sua vez, estão no art. 28 e seguintes da LDA, os quais estabelecem caber ao autor o direito exclusivo de utilizar, fruir e dispor da obra, dependendo de autorização prévia e expressa do autor qualquer utilização da obra.

\footnotetext{
${ }^{5}$ Art. 10, LDA: "A proteção à obra intelectual abrange o seu título, se original e inconfundível com o de obra do mesmo gênero, divulgada anteriormente por outro autor."

Art. L. 112-4, CPI "Le titre d'une oeuvre de l'esprit, dès lors qu'il présente un caractère original, est protégé comme l'oeuvre elle-même."
} 
A legislação brasileira consolida ainda conceitos fundamentais, tais como a distinção entre a obra e a sua fixação, bem como enfatiza que a aquisição do original de uma obra, ou de seu exemplar, não confere ao adquirente qualquer dos direitos patrimoniais do autor, salvo convenção em contrário entre as partes ou previsão expressa da própria lei (art. 37, LDA).

Finalmente, como o direito à reprodução está diretamente relacionado aos direitos autorais patrimoniais propõe-se a seguir o aprofundamento acerca deste assunto no tocante a necessidade de autorização para reprodução e compartilhamento do material autoral.

\subsection{Direitos de reprodução}

O direito de reprodução é um dos pontos principais dos direitos patrimoniais do autor e é traduzido pela faculdade de que dispõe o autor de decidir pela exploração ou não de sua obra, por quaisquer dos meios existentes, tanto na sua forma original, quanto depois de transformada. Enquanto que a exploração da obra se configura pela sua multiplicação em exemplares.

A reprodução é definida no art. $5^{\circ}$, VI da LDA como:

a cópia de um ou vários exemplares de uma obra literária, artística ou científica ou de um fonograma, de qualquer forma tangível, incluindo qualquer armazenamento permanente ou temporário por meios eletrônicos ou qualquer outro meio de fixação que venha a ser desenvolvido (BRASIL, 1998).

Assim, conforme o texto legal, é irrelevante a pluralidade de cópias, visto que a reprodução de somente um exemplar caracteriza a reprodução da obra. Ademais, conforme a parte final do inciso ora mencionado, armazenar por meios eletrônicos ou outros suportes também configura a reprodução da obra. Portanto, como o autor detém o direito exclusivo de utilizar, fruir e dispor de sua obra, considera-se que a digitalização da obra protegida bem como a utilização desse arquivo digital permanecem abrangidas pela condição de exclusividade e, conforme o texto legal, somente o autor poderia autorizar a digitalização de sua obra, o armazenamento do arquivo e sua disponibilização online.

Assim, é necessário que o aluno, usuário do material do EAD, esteja a par dos riscos decorrentes da reprodução, da divulgação e do compartilhamento de conteúdo sem autorização expressa do titular dos direitos patrimoniais de autor. Para se reproduzir material protegido por direitos autorais é necessário autorização prévia e expressa do autor, conforme previsto no art. 29 da LDA. Na falta desta autorização, em caso de reprodução a contrafação será configurada (art. 5 ${ }^{\circ}$, VI e VII, LDA), mesmo se a reprodução tiver ocorrido sob o pretexto de aprimorar/modificar a obra (art. 33, LDA), para fins didáticos, ou independente de 
lucro ou prejuízo causado por aquele que reproduziu a obra, pois essa reprodução por si só já é considerada uma violação ao monopólio do autor (art. 102, LDA) .

Em alguns casos, criações que, embora estejam protegidas podem ser consideradas livre de direitos, desde que pertençam ao domínio público ou sejam consideradas por seu criador como tal a partir de sua criação. De fato, uma obra é considerada em domínio público quando a sua proteção tiver expirado, ou seja, 70 anos contados de $1^{\circ}$ de janeiro do ano seguinte ao falecimento do autor (art. 41, LDA). A partir desde período, a obra poderá ser reproduzida e distribuída livremente. O mesmo ocorre, ainda, nos casos previstos no art. 45, LDA (autores falecidos que não tenham deixado sucessores ou as obras de autor desconhecido, ressalvada a proteção legal aos conhecimentos étnicos e tradicionais).

De qualquer forma, vale ressaltar, uma obra livre de direito tem o seu conteúdo legalmente protegido, mas por vontade de seu autor ela poderá ser livremente reproduzida, modificada ou distribuída. Tais direitos são concedidos com o intuito de incentivar a livre circulação das criações e permitir ao público acesso livre.

\subsection{Autorização do autor}

A LDA estabelece no art. 29 que depende de autorização prévia e expressa do autor a utilização da obra por quaisquer modalidades como, por exemplo, a reprodução e o armazenamento em computador. Logo a utilização sem licença de uma obra protegida, será de qualquer maneira considerada uma infração aos direitos autorais do autor, tanto patrimoniais como morais.

O simples ato de copiar uma página na Internet, assim como a fotocópia de um livro, a cópia de um software, a utilização de imagens ou músicas em um site, bem como escanear um texto e disponibilizá-lo como material de apoio em um curso EAD, sem autorização do titular dos direitos autorais, também constitui uma violação de direitos autorais.

Realmente, a permissão e a concessão para uso de obras criadas deve ser feita pela licença de uso, prevista no art. 49 da LDA e sujeitas às disposições do Código Civil. Para isso, do ponto de vista da legalidade estrita, em qualquer desses casos, um contrato deve ser celebrado entre o autor (e/ou titular dos direitos patrimoniais de autor) e o possível utilizador da obra licenciada (no caso do EAD, a instituição de ensino responsável pelo curso), no qual restará determinada a forma e as condições para o uso da obra objeto do contrato. 
Outra alternativa é a licença Creative Commons (CC), utilizada por quem deseja compartilhar via web os seus trabalhos. A CC abrange possibilidades que vão da proibição total de uso de uma obra (todos os direitos reservados) ao domínio público. Tais licenças, amplamente utilizadas no meio digital, permitem simultaneamente ao autor preservar os seus direitos e permitir algumas formas de utilização de sua criação. Com a adoção das licenças Creative Commons, é dispensada a necessidade de autorização prévia do autor, o que viabiliza o uso da obra sem infrações aos direitos autorais.

Relativamente à licença CC, Wachowicz e Proner (2012) explicam:

As politicas de creative commons podem também somar-se às políticas de acesso ao
saber e ao conhecimento. Daí a proposta de adoção da Creative Commons (produção
colaborativa), que evolui para a constituição de uma verdadeira economia das redes
de informação baseada na colaboração [...] Os commons têm sido definidos como
espaços institucionais em que podemos praticar um tipo particular de liberdade, a
liberdade em relação a restriçães que são normalmente impostas pelos requisitos dos
mercados. Não existe consenso acerca da aplicação dos commons, mas é fato que a
ideia tem sido conectada a valores de liberdade, criatividade, democracia e mais
especificamente ao direito de autor. [...] O desafio reside em combinar a legítima
proteção aos autores (inclusive no que concerne à melhor remuneração destes), e as
inúmeras oportunidades de convergências tecnológicas, que favorecem o sistema
nacional de propriedade intelectual moderna, promovendo assim uma sociedade
menos desigual ao acesso à cultura e ao conhecimento (WACHOWICZ; PRONER,
2012, p. 25-26).

No âmbito específico da legislação brasileira, contudo, é obrigatória a obtenção da permissão expressa do titular dos direitos sobre objeto antes de seu uso, caso contrário, a reprodução é ilegal, viola o direito patrimonial do autor e será passível de sanção (art. 102, LDA). Da mesma forma, é proibida a reprodução que modifique ou deturpe o objeto sem a devia permissão, sob pena de violação ao direito moral (art. 103, LDA). É necessário ter em mente que o copista, contrafator ou falsificador, pode ser tanto a pessoa que disponibiliza meios para a reprodução das obras como aquele que altera o seu conteúdo. Além disso, na prática, as pessoas que disponibilizam arquivos de material protegido online, bem como aquelas que os utilizam sem as devidas referências autorais podem ser corresponsáveis pela infração.

\subsection{Exceção à autorização: a extinta exceção da cópia privada}

A Lei $n^{\circ} 5.988$ de 1973, revogada pela atual lei de direitos autorais, ao tratar das limitações aos direitos autorais, trazia em seu artigo 49, inciso II a previsão da cópia privada, que não representava ofensa aos direitos do autor: a reprodução, em um só exemplar, de qualquer obra, contanto que não se destine à utilização com intuito de lucro. 
Todavia, a partir da Lei 9.610/98 a cópia integral de qualquer obra tutelada pelo direito de autor tornou-se proibida, admitindo-se somente a cópia de 'pequenos trechos' para uso exclusivamente pessoal do copista e sem o intuito de obter lucro. Mas qual seria, de fato, a extensão desses pequenos trechos em um material didático escrito ou audiovisual?

Para Hildebrando Pontes (2009), a própria redação do art. 46, II, LDA, que é uma limitação dos direitos do autor, devido ao seu conteúdo incongruente, é de impossível aplicação prática. Segundo ele, ainda que o atual diploma autorize a reprodução de "pequenos trechos" em oposição a reprodução integral da obra, essa expressão é subjetiva, de impossível mensuração, tornando inaplicável o conteúdo previsto na lei.

Ainda em vigor na legislação francesa, o instituto da cópia privada é considerado uma exceção ao monopólio do titular de direitos autorais sobre o objeto protegido e não um direito do utilizador. A exceção da cópia privada permite que qualquer pessoa reproduza livremente um objeto protegido desde que tenha sido obtido licitamente, sua reprodução seja destinada ao âmbito privado e sem intuito comercial, e tal exceção está prevista expressamente no art. L. 122-5, do CPI.

Por outro lado, é importante ressaltar que embora a LDA não permita expressamente a cópia integral de exemplar para uso privado, a regra dos três passos, presente no art. 9.2 da Convenção de Berna e no art. 13 do Acordo TRIPS, dos quais o Brasil é signatário, estabelecem os limites aos direitos autorais quando os seguintes requisitos são atendidos: 1) que sejam casos especiais; 2) que não afete a exploração normal da obra; e 3) nem cause prejuízo injustificado aos interesses legítimos do autor.

Assim, quando há equilíbrio de interesses, a jurisprudência considera:

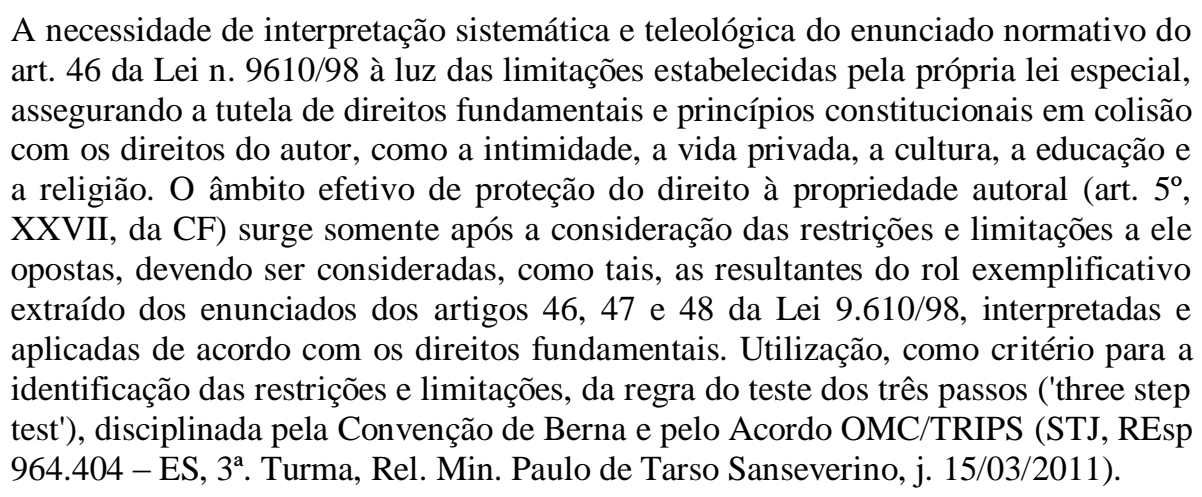

A lei atribui ao autor a competência para decidir o destino de sua obra, autorizar ou proibir a sua utilização por terceiros ou ainda determinar as condições para essa utilização, como, por exemplo, a estipulação de determinada contraprestação por sua utilização. Portanto, 
as limitações previstas no art. 46 da LDA serão sempre uma exceção ao exercício dos direitos autorais.

O objetivo do legislador é proteger, por meio de direitos de propriedade, as criações intelectuais, mas, após mais de 20 anos da publicação da LDA, pode-se afirmar que tal proteção é extensa e relativamente ineficaz. As recentes transformações tecnológicas tornam tudo na vida mais efémero. De fato, a velocidade imediata na transmissão das informações e conteúdos audiovisuais deixou de justificar tão extensa e restrita proteção.

As limitações e exceções previstas nos artigos 46 ao 48 da LDA, que dispensam a necessidade de autorização e/ou remuneração do titular de direitos, não abrangem a utilização para fins acadêmicos, de estudos e pesquisa. Por isso, o usuário final resta prejudicado, já que muitas vezes acaba infringindo o texto legal por falta de conhecimento preciso, por falta de opção e/ou devido a dificuldade de acesso às obras já esgotadas.

Não obstante, vale ressaltar, a legislação norte-americana, que adota o sistema de copyright, prevê o uso da expressão 'fair use', em português 'uso justo', pelo qual o uso de material protegido é permitido para fins educacionais ou em caso de obras esgotadas para reprodução. Nesses casos, leva-se em conta o propósito e o caráter do uso, a natureza do trabalho reproduzido, a quantidade e a substancialidade, bem como os eventuais efeitos gerados no potencial de mercado. O fair use norteamericano também autoriza as cópias integrais para uso privado. No Brasil, entretanto, tal prática viola frontalmente o disposto no art. 46, II, da LDA.

Por isso, Marcos Wachowicz (2015) critica a lei autoral brasileira em vigor:

As diversas utilizações das obras intelectuais para o ensino e pesquisa científica são restringidas e mitigadas pela legislação brasileira em vigor. $\mathrm{O}$ instrumento legal básico para uso acadêmico é a citação (inciso XIV do artigo 46 da Lei 9.610), ainda com a restrição inadmissível de passagens (pequenos trechos) para fins justificados (estudo, crítica ou polêmica), o que limita ainda mais a utilização. Com efeito, as utilizações para o ensino e pesquisa são muito mais amplas, podem e admitem usos variados, como para ilustração ou apoio da própria obra.

A reforma da legislação autoral brasileira é necessária para possibilitar novas utilizações, principalmente no tocante ao inciso XVIII do artigo 46 da Lei $\mathrm{n}^{\circ}$ 9.610, para propiciar a reprodução, a tradução e a distribuição de obras como recurso didático pedagógico, a título de ilustração, em atividades educativas ou de pesquisa, no âmbito da educação formal e na extensão necessária para o fim a se atingir, desde que esse uso não tenha finalidade comercial, nem intuito de lucro direto ou indireto e que sejam citados o autor e a fonte, vedada a publicação fora do âmbito a que se destina (WACHOWICZ, 2015, p. 106).

\section{DIREITOS AUTORAIS E O MATERIAL DO EAD}


O direito autoral deve estar integrado ao ordenamento e atualizado relativamente à virtualização das obras que emergiram com o acesso democrático de todos à internet, na era digital. Sobre esse tema, observa Wachowicz (2013):

O confronto das novas tecnologias com a legislação aplicável revelou, dois pontos frágeis: (i) $\mathrm{O}$ primeiro, falta crescente de efetiva proteção dos bens intelectuais existentes no material produzido para EAD, que podem ser transmitidos, copiados, resumidos, permutados e até adulterados, sem qualquer controle do seu legítimo titular, das autoridades estatais ou mesmo internacionais; e, (ii) o segundo, falta do reconhecimento da autoria das pessoas que trabalham com seu esforço intelectual para a criação e para a produção do material de EAD que não se amoldam aos critérios tradicionais de atribuição de autoria (WACHOWICZ, 2013, p. 10).

Nos cursos, tanto presenciais quanto a distância, o objetivo principal é a formação daqueles alunos regularmente matriculados, autorizados a comparecer/assistir online e a realizar as suas anotações para uso privado (releitura e revisões). Anotações estas que não podem, entretanto, ser reproduzidas publicamente (por exemplo, através de arquivos digitais, vídeos ou podcasts), sem o consentimento dos docentes, sob o argumento de que mesmo assistindo às aulas e registrando o que foi lecionado pelos professores, a publicação destas consiste ofensa aos direitos autorais de quem as ministrou (art. 46, IV, LDA).

Ademais, acerca da LDA, Pesserl (2015) afirma que:

A facilidade de copiar, típica do mundo digital, opõe-se à legislação autoral vigente, concebida para o mundo analógico, no qual a cópia depende da expressa previsão e autorização de seu titular. A tecnologia digital trouxe profundas alterações para o conceito de autoria na forma em que se desenvolvem os processos de criação, que hoje são produzidos majoritariamente de forma colaborativa. A interatividade propiciada pelas obras digitais faz com que elas possam ser constantemente alteradas, não apenas por seu criador, mas também pelo usuário, que se torna coautor. E, no entanto, tais condutas - cópia, derivações, e algumas modalidades de transformação criativa - somente são lícitas mediante a acedência do titular de direitos, numa relação desequilibrada com os interesses dos utentes, se verificarmos que o propósito último da lei autoral é a defesa da inovação para a sociedade, e não do interesse privado (PESSERL, 2015, p. 231).

No caso do EAD é patente a complexidade em relação aos direitos autorais do material instrucional dos cursos, pois o conteúdo muitas vezes é produzido por diversos professores, de forma colaborativa entre eles e incremental. Já no caso de obras multimídia, é incerto afirmar se os direitos autorais pertencem aos criadores dos sons e imagens ou aos organizadores (no caso de obras coletivas), enquanto os direitos autorais sobre o software pertencem àquele que encomendou, ao empregador ou ao contratante dos serviços.

A criação e a produção do material $\mathrm{EAD}$, será quase sempre coletiva devido a interação de diversas pessoas (autores), cujas contribuições e esforço intelectual se fundem 
numa criação final. A seguir serão tratadas as classificações da obra de EAD segundo a sua autoria.

\subsection{O professor conteudista e a obra individual}

A autoria pertence, salvo prova em contrário, à pessoa ou às pessoas sob o nome das quais o trabalho é divulgado. Caso contrário, o autor terá que estabelecer a paternidade de seu trabalho (art. 11, LDA).

Conforme leciona Wachowicz (2015), devido a sua forma de elaboração, o material instrucional de EAD dificilmente será de produção totalmente individual, ainda que as empresas de $\mathrm{EAD}$, tanto públicas quanto privadas, contratem professores conteudistas, peritos em certos temas, para escrever e produzir os conteúdos do material EAD. Nesse sentido, de acorcom com Wachowicz (2015):

\footnotetext{
Os professores conteudistas são efetivamente autores dos textos que servirão de base para a produção do material multimídia de EAD que é tutelado pelas regras de direitos autorais. Tais professores conteudistas são remunerados pelo trabalho intelectual realizado, apenas uma vez, na maioria dos casos. A proteção pelo direito autoral denota uma fragilidade na relação jurídica que se estabelece entre o professor conteudista e a empresa de EAD, na medida em que o conteúdo criado poderá ser replicado durante anos para milhares de pessoas, isto sem que o professor conteudista tenha participação econômica, ou ainda, sem que tenha condições de mensurar como se opera a utilização da sua criação visto que, muitas vezes, nunca mais será contatado pela empresa de EAD. Tais questões são relevantes e devem estar previstas no contrato para perfeita tutela dos direitos autorais envolvidos na produção, distribuição e comercialização do material de EAD (WACHOWICZ, 2015, p. 103).
}

A criação do material pode ainda resultar da incorporação de uma obra anterior em uma nova obra sem a colaboração do autor da primeira obra. Essa nova obra é chamada de trabalho "composto" ou "derivado", que, do ponto de vista legal, não poderá ser explorado sem a autorização do autor do primeiro trabalho (art. $5^{\circ}$, VIII, g, LDA).

\subsection{Coautoria ou obra em colaboração}

Se o material didático for realizado com a colaboração de dois ou mais autores, tratase de um trabalho de colaboração pertencente em conjunto aos coautores, que devem assim exercer os seus direitos autorais (morais e patrimoniais) de forma compartilhada (art. $5^{\circ}$, VIII, a e art.15, LDA).

Portanto, durante o processo de criação do material de EAD cada um que participar em conjunto do projeto com seu intelecto de forma relevante, sem que tenha simplesmente 
auxiliado o autor na produção, revisão, atualização ou edição será considerado coautor do material didático produzido.

\title{
4.3 Obra coletiva da empresa de EAD
}

Finalmente, o trabalho pode resultar da iniciativa de uma pessoa física ou jurídica que edita, publica e divulga sob sua direção e nome, e na qual a contribuição pessoal dos vários autores envolvidos em seu desenvolvimento funde-se com o todo para o qual foi concebido, sem que seja possível atribuir a cada um deles um direito distinto sobre o todo da obra. Isso é chamado de obra coletiva, que pertence à pessoa física ou jurídica sob cujo nome foi divulgada (geralmente o empregador) e será a titular de direitos de autor, incluindo os direitos morais (art. $5^{\circ}$, VIII, h, LDA).

\begin{abstract}
A complexidade de trabalhos que envolvem a criação e o desenvolvimento do material de EAD muitas vezes é fruto do esforço intelectual de uma equipe de técnicos, analistas, redatores, que são constituídos e organizados por uma terceira pessoa (física ou jurídica), que teria a atribuição dos seus direitos autorais sobre o bem intelectual produzido. Na criação do material de $\mathrm{EAD}$, o espaço entre a ideia da criação e a produção de um novo material de ensino tem, na sua realização, envolvimento de conhecimentos complexos no que tange a tecnologia, know-how e direitos autorais de terceiros (WACHOWICZ, 2015, p. 104).
\end{abstract}

Durante a produção do material EAD sobre determinado assunto, no projeto podem ser aplicados conhecimento já existentes em outros materiais, tais como trechos de textos, filmes, músicas, ilustrações pertencentes a terceiros que podem estar protegidos pelo direito autoral. Assim, o desenvolvimento deste material de EAD passará pela pelas fases de fusão de conhecimento preexistente sobre o conteúdo; fase de conhecimentos e recursos tecnológicos, bem como pela fase de conhecimento de produção técnica das empresas de EAD, tornando-se impossível atribuir a cada partícipe um direito autoral distinto sobre o conjunto da obra.

Desse modo, como assevera Wachowicz (2015):

No âmbito do direito autoral, a análise da produção de material de EAD é complexa, e, partindo-se do princípio de que estará protegido todo o esforço intelectual humano, implicaria dizer que todos os colaboradores que contribuírem na elaboração, mesmo por intercambiar conhecimentos com outros ramos técnicos (da informática), teriam sua criatividade tutelada pelo direito autoral. Nesse aspecto, é importante apontar com clareza quais são efetivamente as modalidades de licenciamentos para maximizar o acesso à produção do conhecimento (WACHOWICZ, 2015, p. 105).

\section{CONCLUSÃO}

A proposta deste estudo foi elaborar o enquadramento jurídico da proteção dos cursos e materiais didáticos do ensino a distancia pelos direitos autorais. 
Como restou demonstrando, nos cursos de EAD nem sempre é tão simples determinar quem são os autores dos textos e dos materiais instrucionais ofertados aos alunos. Além disso, a facilidade para copiar e colar trechos de textos eletrônicos torna mais difícil o controle do plágio (reprodução de trechos de uma obra sem a devida indicação da fonte, art. 46, III, LDA). Todavia, conforme a legislação brasileira de direitos autorais, outras formas de uso do material autoral, sem a permissão dos titulares de direitos autorais, mesmo que o copista não pretenda adquirir qualquer benefício financeiro, constitui ato de infração, sujeito a sanções civis e penais.

Apesar disso, é inegável a popularização e o crescente número de instituições autorizadas pelo MEC a oferecer cursos a distância nas mais diversas áreas do conhecimento. E isso já determinou grande mudança nos modelos pedagógicos e nos métodos de ensino, atualmente baseados, sobretudo, na produção e na utilização de material instrucional distribuído amplamente por meios digitais.

O avanço da tecnologia, a melhoria na infraestrutura de redes, o desenvolvimento de novos modelos pedagógicos e o fomento à educação a distancia não serão detidos pela legislação, por mais restritiva que ela seja relativamente aos direitos autorai, pois tudo isso se enquadra em um contexto de crise econômica, mas também de busca pela qualidade de vida (bem viver), de flexibilidade, de facilidade e quase gratuidade para a reprodução de informação e de conteúdo digital.

Há, por tudo isso, a necessidade urgente de readequação da legislação de direito autoral à realidade dos fatos e dos cursos de EAD. E o trabalho de revisão e de aprimoramento da legislação tem a dupla missão de encontrar o ponto de equilíbrio entre a proteção patrimonial e moral dos direitos do autor (de maneira a estimular novas criações), o uso privado para fins não comerciais pelos alunos e a promoção da educação de qualidade.

Enquanto não se promove a alteração do texto da lei, propõe-se, quando possível, a utilização da licença Creative Commons, ou, a partir das circunstâncias específicas de cada caso, a interpretação da lei de direitos autorais conforme a Constituição Federal, por meio da ponderação dos valores subjacentes tanto ao princípio de proteção ao direito autoral, quanto ao direito social da educação.

\section{REFERÊNCIAS BIBLIOGRÁFICAS}


BRASIL. Constituição da República Federativa do Brasil de 1988. Disponível em: http://www.planalto.gov.br/ccivil_03/Constituicao/Constituicao.htm Acesso em: 01 jul. 2019.

Decreto 9.057, de 25 de maio de 2017. Disponível em:

http://www.planalto.gov.br/ccivil_03/_Ato2015-2018/2017/Decreto/D9057.htm Acesso em: 17 jul. 2019.

Decreto 75.699, de 6 de maio de 1975. Convenção de Berna para a proteção das obras literárias e artísticas. Disponível em:

http://www.planalto.gov.br/ccivil_03/decreto/1970-1979/d75699.htm Acesso em: 17 jul. 2019.

Lei 5.988, de 14 de dezembro de 1973. Disponível em:

http://www.planalto.gov.br/ccivil 03/leis/L5988.htm Acesso em: 17 jul. 2019.

Lei 9.394, de 20 de dezembro de 1996. Disponível em:

http://www.planalto.gov.br/ccivil_03/leis/19394.htm Acesso em: 17 jul. 2019.

Lei 9.610, de 19 de fevereiro de 1998. Disponível em:

http://www.planalto.gov.br/ccivil_03/LEIS/L9610.htm Acesso em: 01 jul. 2019.

Ministério da Educação. Censo da Educação Superior. Disponível em:

http://portal.mec.gov.br/docman/setembro-2018-pdf/97041-apresentac-a-o-censo-superior-ultimo/file. Acesso em: 09 jul. 2019.

CARON, Christophe. Droit d'auteur et droits voisins. 4 edition. Paris: LexisNexis, 2015.

FRANÇA. Code de la propriété intellectuelle, Version consolidée au 1 juin 2019. Disponível em:

https://www.legifrance.gouv.fr/affichCode.do?cidTexte=LEGITEXT000006069414\&dateTex te $=20190716$ Acesso em: 16 jul. 2019 .

GAUTIER, Pierre-Yves. Propriété littéraire et artistique. 7 édition refondue. Paris: Presses Universitaires de France, 2010.

MAIA, Carmem; MATTAR, João. ABC da EAD. São Paulo: Pearson Prentice Hall, 2007.

PESSERL, Alexandre Ricardo. Notas introdutórias a um estudo do direito de reprodução de oberas autorais no ambiente digital. In: WACHOWICZ, Marcos. (Org.). Direito Autoral \& Marco Civil da Internet. 1 ed. Curitiba: Gedai Publicações/UFPR, 2015, p. 213-236.

PONTES, Hildebrando. Os contratos de cessão de direitos autorais e as licenças virtuais creative commons. $2^{\mathrm{a}}$ edição. Belo Horizonte: Del Rey, 2009.

SANTANA, Ana Cristina Almeida; GIRAFFA, Lucia Maria Martins. Educação a distância e a (re)leitura do esclarecimento de Kant. Interfaces Científicas - Educação, Aracaju, v. 7, n. 1, p. 129-136, out. 2018. Disponível em:

http://repositorio.pucrs.br/dspace/handle/10923/14547 Acesso em: 18 jul. 2019. 
SIMÃO NETO, Antônio; HESKETH, Camile Gonçalves. Didática e design instrucional. Curitiba: IESDE, 2009.

SUPERIOR TRIBUNAL DE JUSTIÇA. Recurso Especial 964.404 ES. Recorrente: Mitra Arquidiocesana de Vitória. Recorrido: Escritório Central de Arrecadação e Distribuição. Relator: Min. Paulo de Tarso Sanseverino, Brasília, 15 de mar. 2011.

TRIBUNAL DE JUSTIÇA DA UNIÃO EUROPEIA. Processo C-145/10. Recorrente: EvaMaria Painer, Recorridos: Standard VerlagsGmbH e outros. Relator: J. Malenovský, Luxemburgo, 1 dez. 2011. Disponível em: http://curia.europa.eu/juris/document/document.jsf?text=\&docid=115785\&pageIndex $=0 \&$ doc $\underline{\text { lang }=p t \& \text { mode }=1 \text { st\&dir }=\& o c c=\text { first } \& \text { part }=1 \& c i d=8563856}$ Acesso em: 05 jul. 2019.

TRIBUNAL DE JUSTIÇA DA UNIÃO EUROPEIA. Processo C-406/10. Recorrente: SAS Institute Inc. Recorrido: World Programming Ltd. Relator: G. Arestis, Luxemburgo, 2 mai., 2012. Disponível em:

http://curia.europa.eu/juris/document/document.jsf?text=\&docid=122362\&pageIndex $=0 \&$ doc lang=pt\&mode=lst\&dir=\&occ=first \&part=1\&cid=8565214 Acesso em: 05 jul. 2019.

WACHOWICZ, Marcos. Direito autoral, recursos educacionais e licenciamentos criativos: acesso à cultura, ao conhecimento e à educação. Em Aberto, Brasília, v. 28, n. 94, p. 96-108, jul./dez. 2015. Disponível em: http://www.gedai.com.br/wp-

content/uploads/2015/10/revista_completa_em_aberto_94_marcoswachowicz.compressed1.pdf Acesso em: 01 jul. 2019.

WACHOWICZ, Marcos. Ensino a distância e direitos autorais:

a produção do conhecimento e a sua tutela jurídica. 2013. Disponível em: http://www.gedai.com.br/wp-content/uploads/2015/01/artigo_direito_autoral_ead_0-1.pdf Acesso em: 01 jul. 2019.

WACHOWICZ, Marcos; PRONER, Carol. Movimentos rumo à sociedade democrática do conhecimento. In: WACHOWICZ, Marcos; PRONER, Carol. (Org.). Inclusão tecnológica e direito à cultura: movimentos rumo à sociedade democrática do conhecimento.

Florianópolis: FUNJAB, 2012, p. 15-37. 